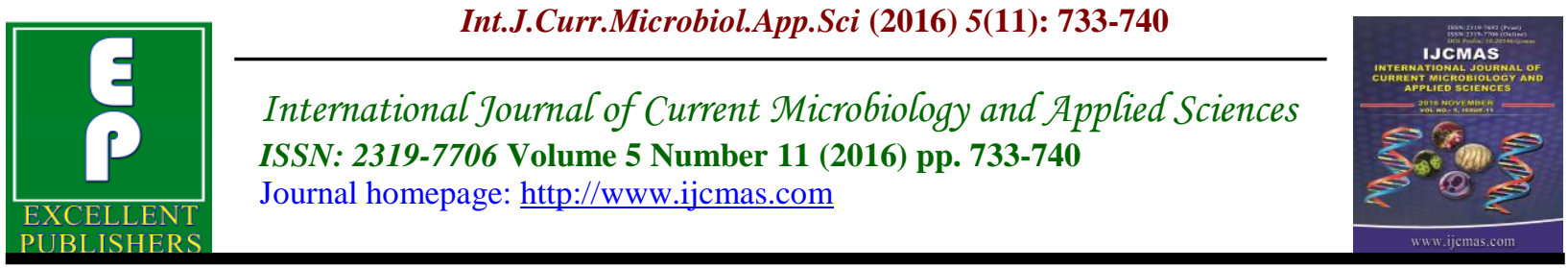

Original Research Article

http://dx.doi.org/10.20546/ijcmas.2016.511.084

\title{
Trends of Seroprevalence and Epidemiology of HIV Infection: A Five Year Tertiary Care Hospital Based Study
}

\author{
Nitin Arun Ambhore, Poonam C. Sayare*, Rajesh P. Karyakarte and Rupali S. Mantri \\ Department of Microbiology, Government Medical College, Akola-444005, Maharashtra, India \\ *Corresponding author
}

Keywords

Human

Immunodeficiency

Virus,

Prevalence,

Epidemiology.

Article Info

Accepted:

26 October 2016

Available Online:

10 November 2016

\section{A B S T R A C T}

HIV prevalence is slowly but steadily declining. HIV counselling and testing services under ICTC are a key entry point to HIV prevalence and care. This study was carried out to estimate the prevalence of HIV infection in tertiary care hospital at Akola. Study was carried out through the analysis of data collected from ICTC. All the essential information was collected from interviewing the attendees. HIV antibodies were tested as per the NACO guidelines. Seroprevalence for HIV infection was found to be $4.51 \%$ (2150/47677). There is decrease in the seroprevalence rate from $6.18 \%$ in 2011 to $3.22 \%$ in 2015 . Seropositive males constituted more than females. Maximum number of clients tested seropositive in the age group of 31 - 40 years $(39.09 \%)$. Self referred clients $(65 \%)$ were in maximum numbers. Unprotected heterosexual contact was the most common mode of transmission of HIV. At the time testing $71.87 \%$ HIV infected clients showed CD4 count less than 500 cell $/ \mathrm{mm}^{3}$. This study provides an important clue to understand the epidemiology of HIV/AIDS in and around the Akola region. This helps to establish an effective local planning for care, treatment and preventive strategies.

\section{Introduction}

The global pandemic of Human Immunodeficiency Virus/Acquired Immunodeficiency Syndrome (HIV/AIDS) in its third decade has grown into a major public health problem of alarming magnitude (Dash et al., 2013). There are approximately 34 million people currently living with HIV worldwide and about 30 million people have died of AIDS related causes since the beginning of the epidemic (UNAIDS, 2011, 2012).Though India is categorized as a low HIV prevalence nation, it has the third largest number of people living with HIV/AIDS in the world with total number of people living with HIV (PLHAs) estimated as 21.17 lakhs in 2015 (Goel et $a l .$, 2016). According to National AIDS Control Organization of India (NACO), the prevalence of AIDS in India has declined in $2015(0.26 \%)$ as compared 2001-2003 (0.38\%) (NACO, 2016).

The spread of HIV in India has been uneven. HIV epidemics are more severe in the southern half of the country and the far north-east. As per NACO report the highest estimated prevalence of adult HIV infection is found in Manipur (1.40\%), followed by 
Andhra Pradesh (0.90\%), Mizoram (0.81\%), Nagaland $(0.78 \%)$, Karnataka $(0.63 \%)$ and Maharashtra $(0.55 \%)$ ( Kalpana et al., 2013).

Early descriptions of HIV epidemiology created a general perception that HIV infection was largely restricted to sex workers, truck drivers, and IDUs. Now the infection has spread further into the general population (Sherwal et al., 2015). Therefore, to create awareness of the HIV infection the National AIDS Control Programme (NACP) started in 1990. It lays maximum emphasis on the widespread reach of information, education and communication on HIV/AIDS prevention (Laghave et al., 2015). Under NACP-III, Voluntary Counseling and Testing Centers (VCTCs) and facilities providing Prevention of Parent to Child Transmission of HIV/AIDS (PPTCT) services are remodelled as an Integrated Counselling and Testing Centre (ICTC).

Till date, no vaccine is available to prevent HIV infection; available treatment can only prolong life to some extent and complete cure is not possible. If we study the epidemiology of HIV, then we can use the collected data in a better way to reduce the incidence of HIV infection by formulating preventive steps. Therefore, the present study was conducted on attendees of ICTC, Department of Microbiology and Immunology of Government Medical College, Akola.

This study was carried out retrospectively to estimate the prevalence of HIV infection in the clients attending ICTC at Government Medical College, Akola, India.

\section{Materials and Methods}

Retrospective hospital record based descriptive study; cross-sectional in design; carried out through the analysis of secondary data collected from ICTC centre;
Department of Microbiology at Government Medical College, Akola, India.

The study included all the attendees of ICTC from January 2011 to December 2015 coming either voluntarily or being referred from various departments of the hospital. All the essential information was collected from the attendees by interviewing them. The variables studied included age, sex, marital status, occupation, pattern of risk behavior etc.

Following the guidelines of NACO, the counselor of the ICTC interviewed the attendees under strict confidentiality. After pre-test counseling and obtaining consent of the attendees, blood samples were collected. HIV antibodies were tested by the three rapid tests protocol as per the guidelines laid down by the World Health Organization (WHO testing strategy III) and the testing policy of NACO, Government of India (NACO, 2007). Samples tested reactive in the first method were subjected to tests with two different rapid tests, the samples were considered as positive when found reactive by all three different methods. All tests were done according to manufacturer's instructions. Data was collected; compiled and analyzed.

\section{Results and Discussion}

Over a period of five years from 2011 to 2015, 47,677 clients were screened for HIV infection. Out of 47,677 clients, 2150 were tested positive for HIV1 infection and three cases were found positive for HIV2 infection. Only one sample was found exclusively positive for HIV 2 and two samples were found positive for HIV1 and HIV2.

In this study the seroprevalence of HIV was found to be $4.51 \%$ (2150/47677). Overall positivity rates among attendees were found 
to be $6.18 \% \quad(569 / 9193), \quad 5.05 \%$ $(506 / 10,002), 4.28 \% \quad(433 / 10,108), 3.76 \%$ $(344 / 9142)$ and $3.22 \%(298 / 9232)$ in the years 2011, 2012, 2013, 2014 and 2015 respectively (figure 1). This shows decrease in the seroprevalence rate from $6.18 \%$ in 2011 to $3.22 \%$ in 2015.

Seropositive males (1296) constituted more than females (854) (figure2). Maximum number of clients tested seropositive in the age group of 31- 40 years $(39.09 \%)$, followed by the age groups of 21-30years $(23.11 \%), 41-50$ years $(20.37 \%)$, above 50 years $(9.62 \%)$ and less than 20 years (7.85\%) respectively. All three HIV-2 cases were males in the age group of 21-50 years. The comparison of seropositivity in various age groups is depicted in figure 3 .

In this study about $90.72 \%$ study population were literate, of which $50.42 \%$ clients had received primary education, $36.33 \%$ received up to higher secondary education, $3.97 \%$ received up to college and above and $9.28 \%$ were uneducated.

The distribution according to marital status showed that $62.21 \%$ clients were married, $13.02 \%$ were unmarried, $12.56 \%$ were widow and $9.3 \%$ were divorcee and $2.88 \%$ with age group less than 14 years.

Occupation wise distribution among the infected clients showed that daily wages constituted $51.62 \%$ of cases, $29.91 \%$ were salaried while $18.5 \%$ were having no specific job and among females about $65.31 \%$ females were housewives. Most of the cases were from the lower middle and lower socio-economic classes. Self referred clients $(65 \%)$ were in maximum numbers followed by referred by government facility $(14.3 \%)$, RNTCP $(8.79 \%)$ and STI clinics $(4.6 \%)$. Record of spouse testing showed that about $28.48 \%$ of the spouses were tested as positive and $71.52 \%$ were tested as negative.
Unprotected heterosexual contact has come out to be the most common mode of transmission of HIV in the present study with the rate of $74.2 \%$.Possibility of transmission through blood and blood products was $2.18 \%$. Least transmission was observed by homosexual route and infected needles \& syringes.

At the time of testing $60.28 \%$ HIV infected clients showed CD4 count less than 350 cell $/ \mathrm{mm}^{3}$ while rest of the infected clients showed CD4 count as $11.59 \%$ (350$500 \mathrm{cell} / \mathrm{mm}^{3}$ ) and $28.13 \%$ (above 500 cells $/ \mathrm{mm}^{3)}$ respectively.

The present study highlights the seroprevalence and epidemiological data of HIV infection among all clients (excluding ANC clients) attending ICTC in a tertiary care hospital at Vidarbha region. The seropositivity in attendees of ICTC has shown a significant decrease from $6.18 \%$ (2011) to $3.22 \%$ (2015). This declining trend of prevalence is attributed to increase awareness about the disease, expanded surveillance systems with an increase in the number of surveillance sites, along with improvements in the quality of laboratory tests for HIV testing (Ramalingam et al., 2013). Sherwal et al., (2013) and Mishra et al., (2016) have mentioned declining trend in prevalence rate from $2008(5.79 \%)$ to $2012(3.26 \%)$ in New Delhi and in 2005$2006(33.26 \%)$ to $2013(6.01 \%)$ at Nagpur region respectively (Sherwal et al., 2013; Mishra et al., 2016). NACO and Goel et al also mentioned declining trend in HIV prevalence. While Vyas et al reported increasing trends in prevalence of seropositivity from period $2002(12.2 \%)$ to 2007 (17.34\%) (Vyas et al., 2009; Goel et al., 2013). The difference in HIV seropositivity in different studies may be attributed to the difference in health seeking facilities and risk behaviours. In contrast to 
the pandemic spread of HIV-1, the HIV-2 epidemic has largely been limited to West Africa. In present study 3(0.000083\%) cases were reactive for HIV-2 which is in accordance to other studies which confirm that HIV-2 is relatively rare in Asia (Agrawal et al., 2010).

This study shows that males $(60.27 \%)$ had higher seropositivity than females $(39.73 \%)$ with male to female ratio 1.54:1. This finding is almost consistent with other studies (Laghawe et al., 2015; Goel et al., 2016). Male preponderance observed in our study might have been due to fact that females are still not availing of the medical facilities as compared to males. Considering the national data based on information, women are less likely to visit clinic/testing centers. Sex-wise distribution of estimated HIV infected female population in India was found to be 39\% (Pradhan et al., 2006). This is because females are generally tested after the diagnosis of their husbands. There are a number of factors-biological, socio-cultural and economic, which make women and young girls more vulnerable to HIV and AIDS. The major source of infection is through heterosexual transmission and as compared to men; women are at a biological disadvantage in contracting HIV infection (Laghawe et al., 2015). Hence, Programs for increasing female attendance in the health care centers should be carried out.

In this study, higher percentage of seropositivity $(39.06 \%)$ was found in age group 31-40 years followed by age group 21 -30 years $(23.01 \%)$. The age groups ranging from 21 years to 50 years cover the (1775/2150) $82.55 \%$ of all seropositive patients. This age distribution of HIV positives corroborates with our national figure and study done by Haider et al where it is observed that most of the cases (about $89 \%$ ) occurred among sexually active persons aged 20- 49 years (NACO 2014,
Haider et al., 2016). About $90.72 \%$ study population were literate in this study which was in line with the findings of studies conducted by Barua et al., and Dash et al., (Dash et al., 2013,Barua et al., 2015). In our study, $9.28 \%$ of clients were illiterate, $50.42 \%, 36.33 \%, 3.97 \%$ clients have done their primary school, secondary school and college and above education. It is observed in present study that $28.5 \%$ clients were in service and $51.59 \%$ clients on daily wages.

Majority (62.21\%) of the HIV seropositives belong to the married group irrespective of their sexes. Couple counselling, testing and partner notification is an important tool in prevention of HIV transmission. In present study it was found that about $28.48 \%$ of the clients had HIV positive sexual partners which was comparable with study of Barua et al and lower than study done by Langare et al(Langare et al., 2011, Barua et al.,2015). Heterosexual contact was the most common mode of transmission worldwide including India which was supported by the findings of our study and various other studies from different parts of India. Transmission through blood transfusions, once a concern in many countries, has been reduced by the routine mandatory screening of blood donations.

HIV testing in India is a voluntary testing i.e. not mandatory or strict for every individual in the community. Taking this point in consideration, the prevalence of HIV testing among the self referred clients to our ICTC centre $(61.39 \%)$ were much higher in comparison to clients referred by other departments like STI clinic (5.34\%), RNTCP clinic ( $12.09 \%$ ) and government facility $(18.37 \%)$.This reflects the awareness of HIV testing among the population. These findings are similar with study by Shrama et al., and Kurapati et al., (Sharma et al., 2009; Kurapati et al., 2012). while contrast to study by Chellaiyan et al., (2014). 
The CD4 count is the most important laboratory indicator of immune function in HIV-infected patients. It is also the strongest predictor of subsequent disease progression and survival according to findings from clinical trials and cohort studies. In our study before initiation of the antiretroviral treatment among the seropositive clients, majority (60.28\%) showed CD4 count less than 350 cells $/ \mathrm{mm}^{3}$. Other studies also observed same findings that the median CD4 count of newly diagnosed patients remains below 350 cells $/ \mathrm{mm}^{3}$ (Althoff et al., 2009; Granich et al., 2010).

Table.1 Socio-demographic variables of HIV seropositive clients

\begin{tabular}{|c|c|}
\hline Variables & Total $(n=2150)$ \\
\hline \multicolumn{2}{|l|}{ Sex } \\
\hline Male & 1296 \\
\hline Female & 854 \\
\hline \multicolumn{2}{|c|}{ Age group in years } \\
\hline$<20$ & 168 \\
\hline 21-30 & 497 \\
\hline $31-40$ & 840 \\
\hline $41-50$ & 438 \\
\hline 50 -above & 207 \\
\hline \multicolumn{2}{|c|}{ Marital status } \\
\hline Married & 1339 \\
\hline Unmarrid & 280 \\
\hline Widow & 270 \\
\hline Divorcee & 199 \\
\hline Children<14 years & 62 \\
\hline \multicolumn{2}{|c|}{ Education } \\
\hline Illiterate & 200 \\
\hline Primary school & 1084 \\
\hline Secondary school & 781 \\
\hline College and above & 85 \\
\hline \multicolumn{2}{|c|}{ Occupation } \\
\hline Daily wages & 1110 \\
\hline Salaried & 643 \\
\hline Non specific job & 397 \\
\hline \multicolumn{2}{|c|}{ Referred by } \\
\hline Self & 1320 \\
\hline Govt. facility & 395 \\
\hline RNTCP clinic & 260 \\
\hline STI clinic & 115 \\
\hline other & 60 \\
\hline
\end{tabular}


Fig.1 Year wise distribution of HIV positive cases

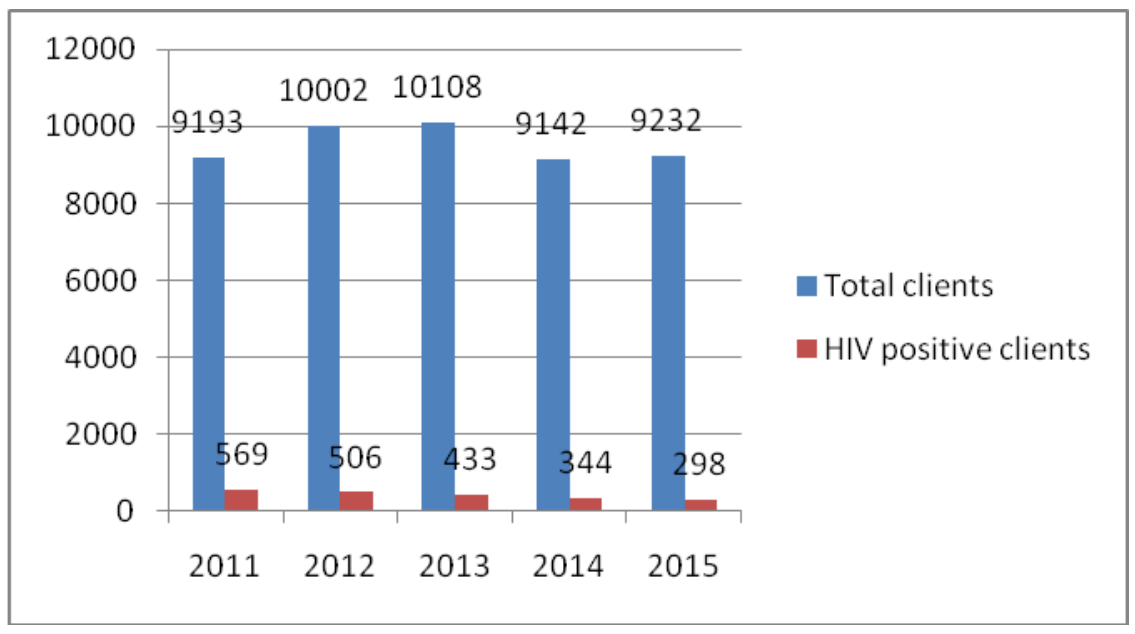

Fig.2 Genderwise distribution of HIV positive cases

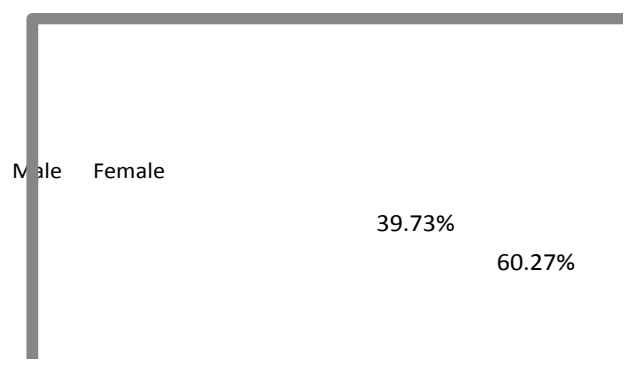

The Post-test session is an important aspect of counseling where the test results were disclosed to the participants. In our study both HIV seropositive and negative clients were counseled efficiently.

In conclusion, declining trend of seroprevalence shows that India's response to the HIV epidemic has achieved significant results in controlling the HIV epidemic. However, it is also imperative that we work to expand these efforts, reaching individuals and communities up to the grass root level with prevention and care programs. Development of the appropriate policies and strategies like education, promoting safe behaviors, counseling, and awareness should be focused.
This study provides an important clue to understand the epidemiology of HIV/AIDS in Vidharbha region of central India and helps as an effective local planning for care, treatment and support of those infected also to formulate preventive strategies for those who are at risk.

\section{Acknowledgments}

The authors are very much thankful to Dr.R.P Karyakrte Sir, Dean, Government Medical College, Akola for his valuable guidance and support. Our sincere gratitude as he has been a constant source of inspiration and motivation for such research activities. Authors also wish to thank the staff of ICTC; Narayan Ingle, Arti Tiwari, 
Savita Borkar and Sumera Khan, for their support and contribution.

\section{References}

Agrawal, S., Sawant, S., Shastri, J. 2010. Prevalence of HIV-2 infection in Mumbai. Indian J. Dermatol. Venereol. Leprol., 76: 709-10.

Althoff, K.N., Gange, S.J., Klein, M.B., et al. 2010. Late presentation for human immunodeficiency virus care in the United States and Canada. Clin. Infect. Dis., 50(11): 15121520.

Annual Report. 2013-14. National AIDS Control Organization. Department of AIDS Control. Ministry of Health \& Family Welfare, Government of India. New Delhi.

Barua, J., Basu, M., Bhattacharya, S., Mukherjee, K., Sinha, D. et al. 2015. Epidemiological Profile of HIV Patients in a Tertiary Care Hospital of Kolkata. J. Pharm. Biomed. Sci., 5: 890-6.

Chellaiyan, V.G., Raut, D.K., Khokhar, A., Singh, S. 2014. Profile and client satisfaction among clients of Integrated Counselling and Testing Centre for human immunodeficiency virus in Delhi. Int. J. Med. Public Health, 4: 380-4.

Goel, V., Kumar, D., Patwardhan, V., Balooni, V., Singhal, S., Singh, S. 2016. Trends of Seroprevalence, Epidemiology and Clinical Presentation of HIV in North India: A Tertiary Care Hospital Based Study, World J. AIDS, 6: 54-58.

Haider, S., Tudu, L., Kashyap, V. 2016. Sociodemographic profile of people attending integrated counselling and testing centre of tertiary care hospital of Jharkhand. Int. J. Community Med. Public Health, 3:
319-22.

Kalpana, K., Saraswati, R. 2013. IOSR J. Humanit Soc. Sci., 8(4): 29-33.

Kurapati, S., Vajpayee, M., Raina, M., Vishnubhatla, S. 2012. Adolescents Living with HIV: An Indian Profile. AIDS reaserch Treat. 1-7.

Laghawe, A., Faujdar, S.S. 2015. Declining Trends in HIV Prevalence: A Tertiary Care Hospital Based 05 Years Retrospective Analysis. 4(6):927-36.

Langare, S., Rajderkar, S., Naik, J., Prabhu, P. 2011. Profile of clients attending an Integrated Counseling and Testing Centre of Tertiary Care Hospital at Sangli District of Maharashtra. IJRTSAT, 1: 124-6.

Mishra, M., Qazi, M., Kurhade, A., Surpam, R., Powar, R. 2016. Correspondence tertiary care hospital in central India. Indian $J$ Med Res., 518-20.

National AIDS Control Organization, Ministry of Health and Family Welfare, Government of India. Detection of HIV infection. In: Guidelines on HIV Testing, March 38-53.

National Institute of Medical Statistics and National AIDS Control Organization 2015 Technical Report India: HIV Estimates- 2015. New Delhi.

Pradhan, B., Ramamani, S. 2006. Gender Impact of HIV and AIDS in India, National AIDS Control Organisation (NACO), National Council of Applied Economic Research (NCAER), United Nations Development Programme (UNDP).

Ramalingam, S., Murugesan, A., Moorthy, S., Manoharan, M. 2013. Recent trends in HIV prevalence in a remote setting of southern India: Insights into arranging HIV control 
policies, J. Infect. Dev. Ctries, 7(11): 838-843.

Sabharwal, E.R. 2015. Four year data from an ICTC of a tertiary care hospital in Jaipur, Rajasthan. Indian J. Med. Microbiol., 33: 187-189.

Sharma, R. 2009. Profile of attendee for voluntary counseling and testing in the ICTC, Ahmedabad. Indian J. sex transm Dis., 30(1): 31-6.

UNAIDS. 2011. AIDS at 30: Nations at the Crossroads.

UNAIDS. 2012. World AIDS Day Report: Results.
Vyas, N., Hooja, S., Sinha, P., Mathur, A., Singhal, A., Vyas, L. 2009. Prevalence of HIV/AIDS and prediction of future trends in northwest region of India: A six-year ICTC-based study. Indian $J$. Community Med., 34: 212-7.

\section{How to cite this article:}

Nitin Arun Ambhore, Poonam C. Sayare, Rajesh P. Karyakarte and Rupali S. Mantri. 2016. Trends of Seroprevalence and Epidemiology of HIV Infection: A Five Year Tertiary Care Hospital Based Study. Int.J.Curr.Microbiol.App.Sci. 5(11): 733-740. doi: http://dx.doi.org/10.20546/ijcmas.2016.511.084 